\title{
Successful tumour necrosis factor (TNF) blocking therapy suppresses oxidative stress and hypoxia- induced mitochondrial mutagenesis in inflammatory arthritis
}

Monika Biniecka', Aisling Kennedy ${ }^{1}$, Chin T Ng${ }^{1}$, Ting C Chang ${ }^{1}$, Emese Balogh ${ }^{1}$, Edward Fox ${ }^{2}$, Douglas J Veale , Ursula Fearon ${ }^{1}$ and Jacintha N O'Sullivan ${ }^{3^{*}}$

\begin{abstract}
Introduction: To examine the effects of tumour necrosis factor (TNF) blocking therapy on the levels of early mitochondrial genome alterations and oxidative stress.

Methods: Eighteen inflammatory arthritis patients underwent synovial tissue oxygen $\left(\mathrm{tpO}_{2}\right)$ measurements and clinical assessment of disease activity (DAS28-CRP) at baseline (T0) and three months (T3) after starting biologic therapy. Synovial tissue lipid peroxidation (4-HNE), T and B cell specific markers and synovial vascular endothelial growth factor (VEGF) were quantified by immunohistochemistry. Synovial levels of random mitochondrial DNA (mtDNA) mutations were assessed using Random Mutation Capture (RMC) assay.

Results: 4-HNE levels pre/post anti TNF- $\alpha$ therapy were inversely correlated with in vivo $\mathrm{tpO}_{2}(P<0.008 ; r=-0.60)$. Biologic therapy responders showed a significantly reduced 4-HNE expression $(P<0.05)$. High 4-HNE expression correlated with high DAS28-CRP $(P=0.02 ; r=0.53)$, tender joint count for 28 joints (TJC-28) $(P=0.03 ; r=0.49)$, swollen joint count for 28 joints (SJC-28) $(P=0.03 ; r=0.50)$ and visual analogue scale (VAS) $(P=0.04 ; r=0.48)$. Strong positive association was found between the number of 4-HNE positive cells and CD4+ cells $(P=0.04 ; r=$ 0.60), CD8+ cells $(P=0.001 ; r=0.70)$, CD20+ cells $(P=0.04 ; r=0.68)$, CD68+ cells $(P=0.04 ; r=0.47)$ and synovial VEGF expression $(P=0.01 ; r=063)$. In patients whose in vivo $\mathrm{tpO}_{2}$ levels improved post treatment, significant reduction in mtDNA mutations and DAS28-CRP was observed $(P<0.05)$. In contrast in those patients whose $\mathrm{tpO}_{2}$ levels remained the same or reduced at T3, no significant changes for mtDNA mutations and DAS28-CRP were found.

Conclusions: High levels of synovial oxidative stress and mitochondrial mutation burden are strongly associated with low in vivo oxygen tension and synovial inflammation. Furthermore these significant mitochondrial genome alterations are rescued following successful anti TNF- $\alpha$ treatment.
\end{abstract}

\section{Introduction}

Mitochondria produce ATP through oxidative metabolism to provide cells with energy under physiological conditions. The mitochondrial electron transport chain (ETC) is also a major cellular source of reactive oxygen species (ROS) as some of the electrons passing to

\footnotetext{
* Correspondence: osullij4@tcd.ie

${ }^{3}$ Department of Surgery, Institute of Molecular Medicine, Trinity Centre for Health Sciences, St James's Hospital, St James's Hospital, St James's Street, Dublin 8, Ireland

Full list of author information is available at the end of the article
}

molecular oxygen are prone to leakage from the chain and get trapped by oxygen, which converts to superoxide [1]. Hypoxia characterised by an inadequate supply of molecular oxygen, can trigger mitochondria dysfunction through ineffective functioning of respiratory complexes of ETC $[2,3]$.

Free oxygen radicals are highly active molecules and increased mitochondrial ROS generation promotes cellular oxidative stress resulting in oxidative mitochondrial DNA (mtDNA) damage and lipid peroxidation. 
Moreover, ROS mediate the stress signalling pathways involving nuclear factor-kappa B (NF- $\kappa \mathrm{B})$ [4]. mtDNA is in the proximity of ROS generation site and has relatively limited repair capacity, which makes it vulnerable to high mutation rates [5]. Mutations and deletions of the mitochondrial genome in genes encoding proteins for subunits of mitochondrial respiratory chain complexes I-V, rRNA and tRNA have been linked to a variety of degenerative human diseases and high levels of mtDNA mutations have been also found in many tumours and cancer cells $[5,6]$.

Oxidative stress, which arises from an imbalance between ROS production and antioxidant defences, results also in lipid peroxidation of cell membrane polyunsaturated fatty acids [7]. The primary products of freeradical attack of biological membranes are lipid hydroperoxides, which can decompose to highly reactive, cytotoxic secondary end products, such as 4-hydroxy-2nonenal (4-HNE) [8]. 4-HNE is an endogenously generated $\alpha, \beta$ unsaturated aldehyde, which is not only a marker of extensive oxidative stress but also can modulate cellular metabolism, inflammatory responses and apoptosis via its effects on transcriptional regulation and protein modification [9]. 4-HNE-induced mitochondrial protein modifications include those involved in the ETC, cellular respiration and Krebs cycle [10]. Moreover, 4-HNE can form adducts on DNA bases and modifies mtDNA thus measurement of such modifications may reflect the level of mitochondrial alterations [11].

Inflammatory arthritis (IA) is a chronic, progressive disorder associated with joint inflammation, synovial tissue hypertrophy, joint effusions and degradation of articular cartilage and bone. The normal synovial tissue is a relatively acellular structure with a lining layer (one to two cells thick) comprised of macrophages and fibroblasts. The morphology of IA synovium is strikingly different. There is a significant increase in the number of blood vessels that are associated with differential vascular morphology. Furthermore, the early vascular changes are accompanied by increased recruitment of macrophages and synovial fibroblast cells in the lining layer, along with infiltration of T, B and plasma cells. The precise mechanisms involved in regulation of persistent synovial infiltration and invasion are unclear, but high levels of TNF- $\alpha$ may be crucial in mediating the pathogenesis of IA. TNF- $\alpha$ is a proinflammatory cytokine, activating the NF- $\kappa \mathrm{B}$ pathway, leading to a downstream cascade of other proinflammatory cytokines $[12,13]$. Moreover, it is known to increase mitochondrial ROS production $[14,15]$ and induce the formation of lipidderived aldehydes [16]; however TNF- $\alpha$-induced mitochondrial mutagenesis has not yet been examined in patients with IA. Current targeted biologic therapies, including anti-TNF- $\alpha$ inhibitors result in greater disease improvement and prevention of joint erosion, although clinical studies on the efficacy of TNF- $\alpha$ blocking agents clearly show that about $40 \%$ of patients receiving this therapy are non-responders.

Recently, we demonstrated that successful biologic therapy significantly improves in vivo synovial hypoxia and it is strongly associated with improvement of joint inflammation [17]. In this study we investigate if successful anti-TNF- $\alpha$ treatment alters the levels of early mitochondrial genome alterations, which can play a crucial role in governing clinical response or resistance. Furthermore, we determine if TNF- $\alpha$ blocking therapy changes the levels of synovial 4-HNE, further confirming the relation between hypoxia, oxidative damage and mitochondrial mutagenesis.

\section{Materials and methods Patient recruitment}

All research was carried out in accordance with the Declaration of Helsinki, and approval for this study was granted by the St. Vincent's University Hospital Medical Research and Ethics Committee. Eighteen patients with active IA (rheumatoid arthritis (RA) $n=14$ and psoriatic arthritis (PsA) $n=4$ ) were recruited from outpatient clinics at Department of Rheumatology, St. Vincent's University Hospital. All patients fulfilled the diagnostic criteria for RA and PsA [18,19]. All patients provided fully informed consent and underwent arthroscopy at baseline (T0) and three months after commencement of TNF blocking therapy (T3). At baseline, 50\% of patients were naive for disease-modifying anti-rheumatic drugs (DMARDs) and corticosteroids; however, all patients including those on DMARDs (methotrexate (MTX) alone $35 \%$, MTX + salazopyrine $10 \%$, and plaquenil alone 5\%) were biologic naive, had active disease, had at least one inflamed knee joint and were due to commence biologic therapy. Clinical and laboratory assessment was performed using standard measures of 28 tender and swollen joint count (DAS28), rheumatoid factor, anti-cyclic citrullinated peptide antibody, erythrocyte sedimentation rate (ESR), C-reactive protein (CRP) and global health visual analogue scale (VAS). All measurements were obtained on the same day prior to baseline and three months after anti TNF- $\alpha$ treatment arthroscopy.

\section{Arthroscopy, measurement of in vivo $\mathrm{tpO}_{2}$ and sample collection}

Under local anaesthetic, patients $(n=18)$ underwent arthroscopy at baseline and three months after commencement of TNF blocking therapy. Arthroscopy of the inflamed knee was performed using a Wolf $2.7 \mathrm{~mm}$ needle arthroscope. Macroscopic synovitis and vascularity were scored on a VAS $(0-100 \mathrm{~mm})$. A $\operatorname{LICOX}^{\circledR}$ 
combined $\mathrm{pO}_{2}$ and temperature probe (Integra Life Sciences Corporation, New Jersey, USA) was used to obtain synovial tissue oxygen partial pressure as previously described [20]. Synovial membrane biopsies were obtained from the site of the oxygen tension measurement and immediately embedded in mounting media for immunohistochemical analysis or snap frozen in liquid nitrogen for mitochondrial mutagenesis analysis.

\section{Immunohistochemistry and scoring}

Immunohistochemistry was performed using $7 \mu \mathrm{m}$ cryostat synovial tissue sections and the DAKO ChemMate Envision Kit (DAKO, Glostrup, Denmark). Sections were defrosted at room temperature for 20 minutes, fixed in acetone for 10 minutes and washed in PBS for 5 minutes. Non-specific binding was blocked using 10\% casein in PBS for 20 minutes. The sections were incubated with primary antibodies against human 4-HNE (Genox, Baltimore, MD, USA), CD4, CD8, CD20, CD68 (all from DAKO, Glostrup, Denmark) and vascular endothelial growth factor (VEGF) (Santa Cruz Biotechnology, Inc., Santa Cruz, CA, USA). IgG control antibodies were used as negative controls. Following primary antibody incubation endogenous peroxidase activity was blocked using $0.3 \%$ hydrogen peroxide for seven minutes at room temperature. Slides were incubated with secondary antibody/HRP (DAKO, Glostrup, Denmark). DAB (1:50) was used to visualise staining, and Mayer's haematoxylin (BDH Laboratories, Poole, UK) was incubated for 30 seconds as a counterstain prior to mounting in Pertex mounting media. Images were captured using Olympus DP50 light microscope and AnalySIS software (Soft Imaging System Corporation, Lakewood, CO, USA). Slides were scored separately for lining and sublining layers using well established and validated semi-quantitative scoring method, where the percentage of cells that were positive for a specific marker was compared with the percentage of cells that were negative [21]. Percentage positivity was graded using 0 to 4 scale, where 0 represented no stained cells, 1 was 1 to $25 \%$ stained cells, 2 was 25 to $50 \%$ stained cells, 3 was 50 to $75 \%$ stained cells, and 4 was 75 to $100 \%$ stained cells.

\section{Mitochondrial random mutation capture assay}

A sub-group of eight patients were selected from the initial cohort to quantify the levels of mitochondrial point mutations before and after treatment. Levels of mitochondrial point mutations in snap frozen synovial biopsies were analysed in a blinded fashion using Mitochondrial Random Mutation Capture assay as described previously [22]. Biopsies were homogenised (Precellys 24, Stretton Scientific Ltd., Stretton, Derbyshire, United Kingdom) in $10 \mathrm{mM}$ Tris- $\mathrm{HCl}, \mathrm{pH}$ 8.0, $150 \mathrm{mM} \mathrm{NaCl}$,
20 mM EDTA, 0.5\% SDS buffer and digested with Proteinase K (Sigma-Aldrich, Dublin, Ireland) at a final concentration of $0.2 \mathrm{mg} / \mathrm{ml}$ and incubated overnight at $56^{\circ}$ C. The mtDNA was extracted using phenol-chloroformisoamyl alcohol (25:24:1 by volume, Sigma-Aldrich, Dublin, Ireland) added in a 1:1 ratio with the lysed tissue, mixed thoroughly by shaking, and centrifuged at more than $12,000 \times g$ for 10 minutes. The aqueous phase was gently removed from the top of the solution, without disturbing the interphase. The aqueous solution was again mixed with phenol-chloroform-isoamyl alcohol in a 1:1 ratio and re-extracted. One-tenth volume of $3 \mathrm{M}$ sodium acetate was added, and the samples were precipitated with 2 to 2.5 volumes of ethanol. The DNA samples were resuspended in $50 \mu 10 \mathrm{mM}$ TrisCl. Ten micrograms of mtDNA were digested with 100 units of TaqaI restriction enzyme (New England BioLabs, Herts, United Kingdom), $1 \times$ BSA and a TaqaI-specific digestion buffer $(10 \mathrm{mM}$ Tris- $\mathrm{HCl}, 10 \mathrm{mM} \mathrm{MgCl} 2,100 \mathrm{mM}$ $\mathrm{NaCl}, \mathrm{pH}$ 8.4) for 10 hours; 100 units of TaqaI being added to the reaction mixture every hour.

PCR amplification was performed in $25 \mu \mathrm{l}$ reactions, containing $12.5 \mu \mathrm{l} 2 \times$ SYBR Green Brilliant Mastermix (Stratagene, Agilent Technologies, Inc., Santa Clara, CA, USA), $0.1 \mu \mathrm{l}$ UDG (New England Biosciences, Herts, United Kingdom), $0.7 \mu \mathrm{l}$ of $10 \mathrm{pM} / \mu \mathrm{l}$ forward and reverse primers (Integrated DNA Technologies, Inc., San Diego, CA, USA), and $6.7 \mu \mathrm{l}$ water. The samples were amplified using a Roche Lightcycler 480 using the following protocol: $37^{\circ} \mathrm{C}$ for 10 minutes and $95^{\circ} \mathrm{C}$ for 10 minutes followed by 45 cycles of $95^{\circ} \mathrm{C}$ for 15 seconds, $60^{\circ} \mathrm{C}$ for 1 minute. Samples were held at $72^{\circ} \mathrm{C}$ for 7 minutes and, following melt curve analysis, immediately stored at $-80^{\circ} \mathrm{C}$. The primer sequences used were as follows: for mtDNA copy number: 5'ACAGTTTATGTAGCTTACCTCC-3' (forward) and 5'TTGCTGCGTGCTTGATGCTTGT-3' (reverse); for random mutations: 5'-CCTCAACAGTTAAATCAACAAAACTGC-3' (forward) and 5'-GCGCTTACTTT GTAGCCTTCA-3' (reverse).

\section{Statistical analysis}

Data are presented as medians and interquartile ranges. Data were assessed using Wilcoxon's signed-rank test or Spearman's rank correlation coefficient as appropriate using the Statistical Package for the Social Sciences (SPSS, Chicago, IL, USA). All $P$ values are two-sided and $P$ values less than 0.05 were considered statistically significant.

\section{Results}

In vivo changes of oxidative stress pre/post anti TNF- $\alpha$ therapy

Eighteen IA patients underwent synovial tissue oxygen tension $\left(\mathrm{tpO}_{2}\right)$ measurements and clinical assessment of 
disease activity (28-joint count disease activity score using C-reactive protein (DAS28-CRP)) at baseline and three months after starting biologic therapy. At T3 patients were categorised according to remission criteria using the DAS28 cut-off less than or more than 2.6. Patients with DAS28-CRP less than 2.6 were defined as responders $(n=7)$ and patients with DAS28-CRP more than 2.6 were defined as non-responders $(n=11)$. In responders, the median baseline $\mathrm{pO}_{2}$ in the synovial tissue was $18.07 \mathrm{mmHg}$ (range 4.3 to $42.2 \mathrm{mmHg}$ ), and was lower than in those patients at $\mathrm{T} 3$ (median $\mathrm{tpO}_{2}$ $39.25 \mathrm{mmHg}$ (range 24.7 to $68.2 \mathrm{mmHg}$ )). Of clinical responders, $86 \%$ had a corresponding increase in their synovial $\mathrm{tpO}_{2}$ measurements. In non-responders the median baseline $\mathrm{pO}_{2}$ was $23.75 \mathrm{mmHg}$ (range 6.8 to $46.4 \mathrm{mmHg}$ ), and their median $\mathrm{pO}_{2}$ level after biologic therapy was $19.78 \mathrm{mmHg}$ (range 10.5 to $39.6 \mathrm{mmHg}$ ). In clinical non-responders, $64 \%$ patients showed decrease in their synovial $\mathrm{tpO}_{2}$ levels at T3. Furthermore, $\mathrm{tpO}_{2}$ levels did not differ significantly between baseline patients with RA and those with PsA ( $n=14$ RA, $n=4$ PsA). The median oxygen tension for RA was $23.5 \mathrm{mmHg}$ and for PsA was $14.5 \mathrm{mmHg}(P=0.3)$.
To determine whether biologic treatment changes the levels of synovial oxidative damage, the number of 4HNE positive cells was assessed in both lining and sublining layers of synovial tissue. Figures $1 \mathrm{a}$ and $1 \mathrm{~b}$ show representative images of 4-HNE expression levels in responders at T0 and T3, respectively. Figure 1c graphically illustrates significantly reduced cytoplasmic 4-HNE expression in sublining layer in patients who successfully responded to anti-TNF- $\alpha$ therapy $(P<0.05)$. No significant differences in the levels of cytoplasmic 4-HNE expression pre/post therapy were found in non-responders (Figures 1d to 1f). In addition, the levels of 4-HNE did not differ significantly between baseline patients with RA and those with PsA $(P=0.6)$.

Previously, we demonstrated significant baseline inverse correlation between $\mathrm{tpO}_{2}$ measurements and 4HNE expression [20]. In this study we extend these findings and demonstrate that change in $\mathrm{tpO}_{2}$ is also significantly and inversely correlated with changes in 4HNE levels pre/post biologic therapy $(P<0.008 ; \mathrm{r}=$ -0.60 ; Table 1). It suggests that as synovial tissue becomes less hypoxic oxidative stress is decreased. Furthermore, when patients were categorised according
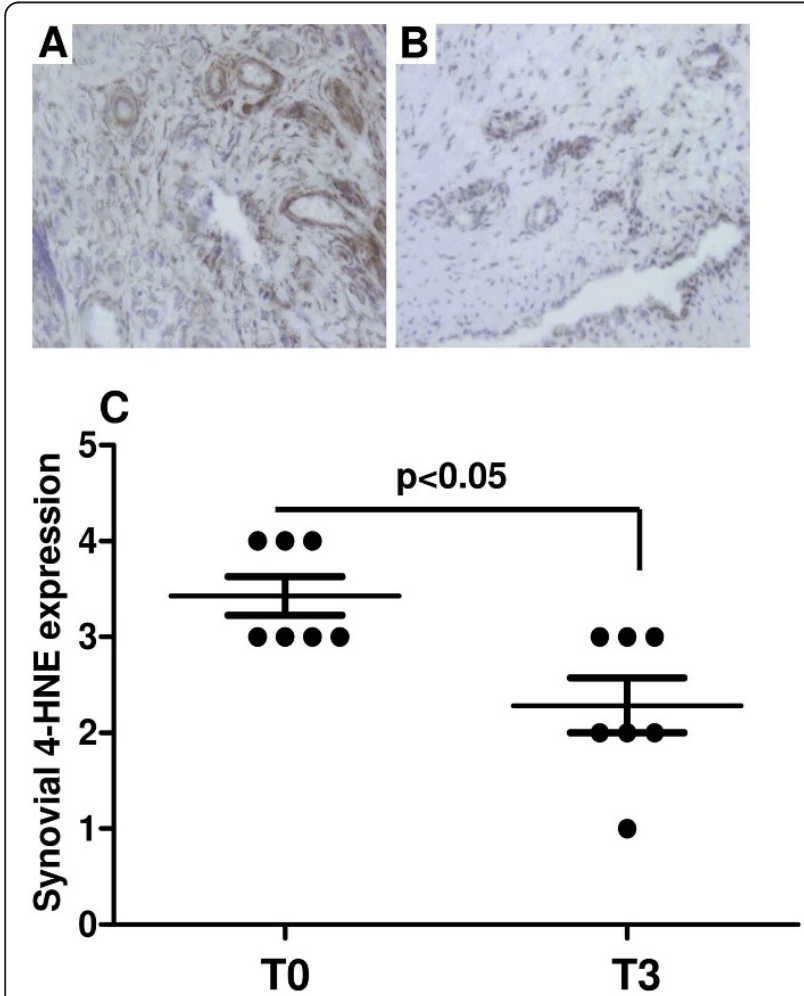
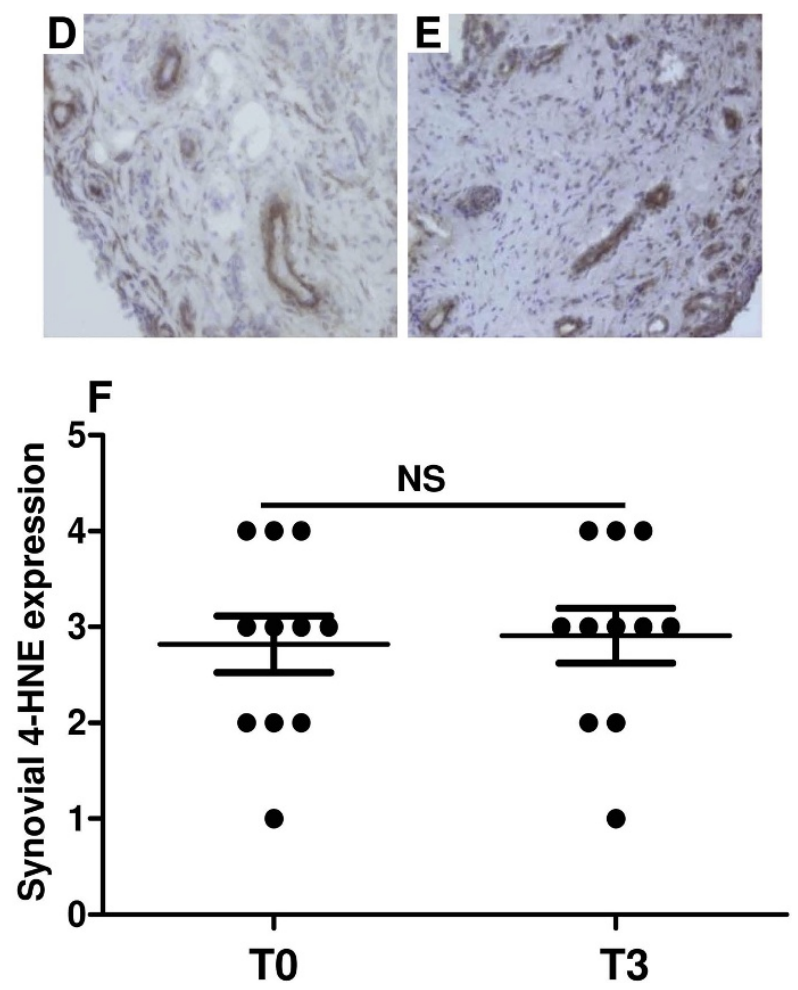

Figure 1 Representative pre/post immunohistochemical images of 4-HNE expression and their graphical representation. (a to c) Responders. (d to f) Non-responders. T0 is time at baseline; T3 is three months after anti-TNF- $\alpha$ treatment. (a to b) Biologic therapy responders showed lower synovial 4-hydroxy-2-nonenal (4-HNE) expression at (b) T3 compared with their (a) T0 levels. (c) Graphical illustration of synovial 4-HNE levels at T0 and T3 $(P<0.05)$. (d to e) No significant 4-HNE changes were seen between (d) T0 and (e) T3 in patients who did not respond to therapy. (f) Graphical representation of synovial 4-HNE levels in non-responders at T0 and T3. 
Table 1 Spearman's rank test correlations of 4-HNE microscopic scores in synovial tissue pre/post anti TNF- $\alpha$ therapy with clinical parameters

\begin{tabular}{ccc}
\hline 4-HNE & r-value & $\boldsymbol{P}$ value \\
\hline $\mathrm{tpO}_{2}$ & -0.60 & 0.008 \\
$\mathrm{DAS} 28-\mathrm{CRP}$ & 0.53 & 0.02 \\
$\mathrm{TJC}-28$ & 0.49 & 0.03 \\
$\mathrm{SJC}-28$ & 0.50 & 0.03 \\
VAS & 0.48 & 0.04
\end{tabular}

DAS28-CRP, 28-joint count disease activity score using C-reactive protein; 4HNE, 4-hydroxy-2-nonenal; SJC-28, swollen joint count for 28 joints; TJC-28, tender joint count for 28 joints; $\mathrm{tpO}_{2}$, in vivo tissue oxygen tension; VAS, visual analogue scale.

to their changes in $\mathrm{tpO}_{2}$ before and after therapy, a significant reduction in the number of 4-HNE positive cells was observed only in patients who had higher oxygen levels at T3 compared with T0 (data not shown).

\section{Synovial oxidative stress and clinical markers}

The relation of oxidative stress marker and clinical markers pre/post anti-TNF- $\alpha$ therapy is shown in Table 1 . We found significant positive correlations between levels of 4-HNE and DAS28-CRP $(P=0.02 ; \mathrm{r}=0.53), 4-\mathrm{HNE}$ and tender joint count (TJC)-28 $(P=0.03 ; \mathrm{r}=0.49)$, 4HNE and swollen joint count (SJC) $-28(P=0.03 ; \mathrm{r}=$ $0.50), 4-\mathrm{HNE}$ and VAS $(P=0.04 ; \mathrm{r}=0.48)$. These results demonstrate a link between oxidative stress and clinical parameters of disease activity and suggest that microscopically assessed levels of 4-HNE may closely reflect clinical scores of IA.

\section{Synovial levels of oxidative stress, inflammation and angiogenesis pre/post biologic therapy}

Levels of lipid peroxidation were correlated with specific markers of T-cells (CD4 and CD8), B-cells (CD20), and macrophages (CD68). Table 2 demonstrates significant positive associations between the number of 4-HNE positive cells and $\mathrm{CD} 4^{+}$cells $(P=0.04 ; \mathrm{r}=0.60), \mathrm{CD} 8^{+}$ cells $(P=0.001 ; \mathrm{r}=0.70), \mathrm{CD} 20^{+}$cells $(P=0.04 ; \mathrm{r}=$ $0.68)$ and $\mathrm{CD}^{+} 8^{+}$cells $(P=0.04 ; \mathrm{r}=0.47)$. Furthermore, high 4-HNE expression correlates with high level of

Table 2 Spearman's rank test correlations of 4-HNE synovial tissue pre/post anti TNF- $\alpha$ therapy with synovial inflammation and angiogenesis

\begin{tabular}{ccc}
\hline 4-HNE & r-value & $\boldsymbol{P}$ value \\
\hline CD4 I & 0.60 & 0.04 \\
CD8 sl & 0.70 & 0.001 \\
CD20 sl & 0.68 & 0.04 \\
CD68 II & 0.47 & 0.04 \\
VEGF bv & 0.63 & 0.01
\end{tabular}

bv, blood vessel; CD4 and CD8, T-cell markers; CD20, B-cell marker; CD68, marker of macrophages; 4-HNE, 4-hydroxy-2-nonenal; II, lining layer; sl, sublining layer; VEGF, vascular endothelial growth factor.
VEGF angiogenic marker $(P=0.01 ; \mathrm{r}=0.63$; Table 2$)$. We have also performed the colocalisation staining between synovial 4-HNE and all cellular specific markers and observed 4-HNE expression in T-cells, B-cells, macrophages and cells of blood vessels.

As higher levels of 4-HNE are strongly associated with high VEGF expression and the number of inflammatory cells pre/post therapy, it may suggest a key role of oxidative stress in driving inflammation and angiogenesis, two crucial processes involved in progression of IA.

\section{Effect of biologic therapy on mitochondrial mutagenesis}

To determine whether biologic therapy alters mitochondrial genome instability, random mutation capture assay was performed at baseline and three months after treatment in a sub-group of eight patients. Patients were categorised into two groups, those whose $\mathrm{tpO}_{2}$ levels improved after treatment $(n=4)$ and those whose in vivo oxygen level remained the same or reduced after three months therapy $(n=4)$. Figure $2 \mathrm{a}$ shows pre/post tpO $\mathrm{O}_{2}$ changes in patients who had a significant increase in in vivo oxygen measurements after treatment in comparison with their baseline levels $(P<0.05)$. This was associated with significantly reduced frequency of mitochondrial point mutations in comparison with baseline levels $(P<0.05$; Figure $2 \mathrm{~b})$ and with significantly lower DAS28-CRP scores at T3 than before treatment $(P<$ 0.05 ; Figure 2c). In contrast, no significant changes in the pre/post levels of mtDNA mutations (Figure 2e) and DAS28-CRP (Figure 2f) were observed in patients who showed no improvement in in vivo $\mathrm{tpO}_{2}$ levels post treatment $(P<0.05$; Figure $2 \mathrm{~d})$. This data may suggest mitochondrial genome alterations as a consequence of elevated synovial hypoxia. In addition, we found that hypoxia-induced mitochondrial mutagenesis was positively correlated with clinical markers of IA. As shown in Table 3 we found significant associations between the levels of mitochondrial point mutations and DAS28CRP $(P=0.01 ; \mathrm{r}=0.83)$, CRP $(P=0.02 ; \mathrm{r}=0.77)$ and ESR $(P=0.04 ; \mathrm{r}=0.73)$.

\section{Discussion}

Chronic inflammatory arthropathies, such as RA and PsA, are characterised by complex chronic inflammatory processes. Oxygen metabolism is important in synovitis and joint destruction [23]. ROS stimulates synovial fibroblasts to secrete matrix metalloproteinases, inhibits cartilage proteoglycan synthesis and accelerates bone resorption [24,25]. Previously, we have demonstrated profoundly hypoxic synovial environment of the inflamed joint (approximately 3\%) [26]. Furthermore, we have shown that biologic anti-TNF- $\alpha$ therapy significantly increased the synovial in vivo tpO $\mathrm{O}_{2}$ levels only in those patients who respond to anti-TNF- $\alpha$ therapy [17]. 


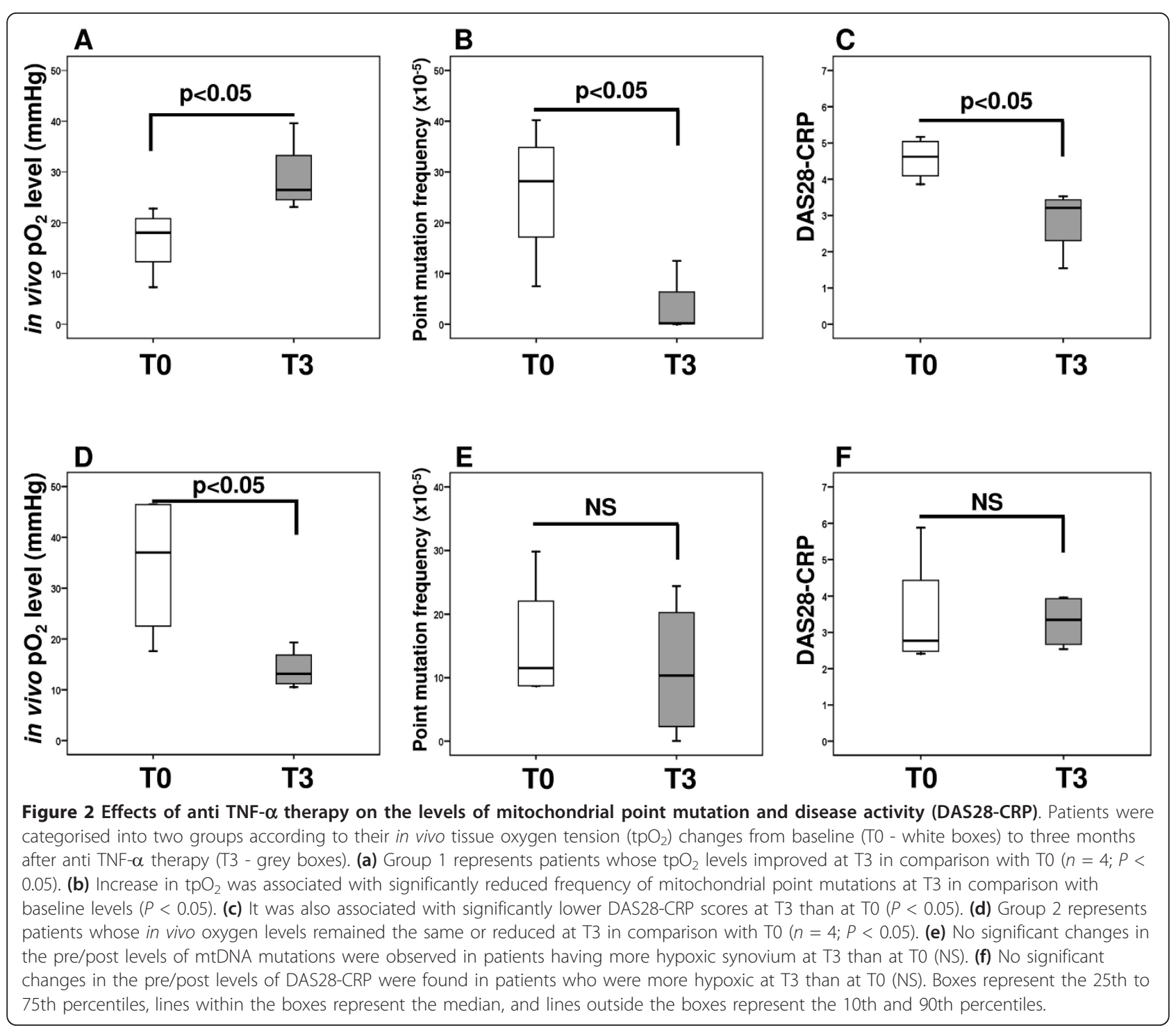

In this study we examine the effect of TNF-blocking therapy on mitochondrial mutagenesis and synovial oxidative stress profiles. We report for the first time that the increase in $\mathrm{tpO}_{2}$ levels observed in responders is associated with significant decrease and strong inverse correlation of synovial lipid peroxidation. In addition, increases in $\mathrm{tpO}_{2}$ significantly reduces the levels of

Table 3 Spearman's rank test correlations of mitochondrial point mutations pre/post anti TNF- $\alpha$ therapy with clinical parameters

\begin{tabular}{ccc}
\hline Mitochondrial point mutations & r-value & $\boldsymbol{P}$ value \\
\hline DAS28-CRP & 0.83 & 0.01 \\
CRP $(\mathrm{mmg} / \mathrm{L})$ & 0.77 & 0.02 \\
ESR $(\mathrm{mm} / \mathrm{hr})$ & 0.73 & 0.04 \\
\hline
\end{tabular}

CRP, C-reactive protein; DAS28-CRP, 28-joint count disease activity score using C-reactive protein; ESR, erythrocyte sedimentation rate. random mitochondrial mutations, presumably as a result of decreased oxidative stress profile.

TNF- $\alpha$ affects many cellular processes, such as activation of phospholipases [27], proteases [28] and DNA damage [29]. Mitochondrially derived ROS are strongly implicated in TNF- $\alpha$ cytotoxicity and may mediate the activation of transcriptional factor NF- $\kappa \mathrm{B}$, which in turn can stimulate mitochondrial NADPH oxidase $[15,30]$. Inhibition of ETC complex III by antimycin A increases ROS and inhibits TNF- $\alpha$ triggered NF- $\kappa \mathrm{B}$ activation, highlighting the importance of the ETC in TNF- $\alpha$ cytotoxicity [31]. Recently, we have shown that hypoxia is an important stimulus of TNF- $\alpha$ secretion, where higher levels of synovial fluid TNF- $\alpha$ were detected in patients with synovial tpO $\mathrm{O}_{2}$ less than 20 $\mathrm{mmHg}$ than in those with $\mathrm{tpO}_{2}$ more than $20 \mathrm{mmHg}$ [26]. 
Oxidative stress arising from overproduction of ROS leads to formation of reactive aldehydes such as 4-HNE. Mitochondrial are primed for attack by 4-HNE and formation of adducts between 4-HNE and mitochondrial components. Detection of 4-HNE-mitochondrial protein adducts can reflect mitochondrial dysfunction and oxidative stress [32]. We have previously assessed the expression of synovial lipid peroxidation in IA patients and demonstrated a significant inverse correlation between 4-HNE expression and oxygen tension of the inflamed join, probably reflecting mitochondrial damage [20]. Mitochondrial membrane components are targets for 4-HNE modification and the adenine nucleotide translocator in the inner mitochondrial membrane is affected by lipid peroxidation [33]. This study in the first to show that patients who respond to TNF-blocking therapy show a significant increase in $\mathrm{tpO}_{2}$ and this is associated with reduced 4-HNE levels. In contrast, in non-responders there is no change in in vivo oxygen levels and subsequently no change in 4-HNE levels. These data suggest that as the joint tissue becomes less hypoxic, a corresponding reduction in oxidative stress is affected. Previous studies have demonstrated positive effects of anti-TNF- $\alpha$ treatment on oxidative damage in RA, where urinary levels of oxidative DNA damage and lipid peroxidation were significantly reduced at three months therapy [34]. However, our study considerably extends the above reports and shows direct evidence of a significant reduction of oxidative stress in relation to in vivo hypoxia measurements.

We have recently demonstrated that increased $\mathrm{tpO}_{2}$ levels after successful anti-TNF biologic therapy is associated with reduced disease activity and macroscopic vascularity [17]. Furthermore, we have also reported that high synovial 4-HNE levels positively correlated with clinical disease activity scores in patients prior to receiving TNF- $\alpha$ blocking therapy [20]. In this study the same parameters were assessed in patients after antiTNF- $\alpha$ treatment and we found significant positive association between synovial 4-HNE expression and clinical measures of arthritis.

Several cellular and environmental sources of synovial oxidative stress have been proposed, including activated neutrophils, monocytes and macrophages, hypoxia and vascular changes. Furthermore, studies by Remans et al. indicated synovial $\mathrm{T}$ lymphocytes as the main generators of intracellular free radicals in RA patients [35]. We demonstrate a correlation between oxidative stress, inflammation and angiogenesis, where increase in $\mathrm{tpO}_{2}$ and reduce oxidative stress observed in responders is associated with lower microscopic scores of T-cells (CD4 and CD8), B-cells (CD20), macrophages (CD68) and angiogenesis (VEGF). Experiments using 4-HNEmodified antigens of $\mathrm{T}$ and $\mathrm{B}$ cells showed rapid autoimmune response, suggesting that $\mathrm{B}$ and $\mathrm{T}$ cell modification by 4-HNE may result in the onset of autoimmune reactions or even autoimmune disease processes [36]. The link between oxidative lipid modifications and activation of the inflammatory potential of macrophages has been also suggested [37]. In human osteoarthritic chondrocytes 4-HNE induces prostaglandin E release and cyclooxygenase-2 (COX-2) expression, providing evidence for the role of 4-HNE as redox-sensitive signalling mechanisms of inflammatory response [38]. Furthermore, 4-HNE elevated VEGF secretion has been shown in retinal pigment epithelial cells [39] and vascular smooth muscle cells [40]. This correlation of VEGF expression and 4-HNE supports our current findings.

RA has many features of autoimmune disease; however, some studies suggest inflammation-independent joint destruction [41]. It has been shown that elevated production of ROS at the sites of chronic inflammation has genotoxic effects and increases the likelihood of mutagenic events. In RA, local exposure to oxidative stress was found to induce genetic changes and was proposed as a mechanism that permanently alters and imprints synovial cells $[42,43]$. Furthermore, oxidative stress can suppress expression of DNA repair enzymes in inflamed synovium such as DNA mismatch repair system that might potentially limit the accumulation of mutations [44]. Other extensive studies demonstrated synovial p53 mutations, which are characteristic DNA damage caused by oxidative stress. High expression of p53 was found in synovial tissue from longstanding RA patients and lower in early RA patients, osteoarthritis (OA) and reactive arthritis patients [45]. This oxidative DNA damage of $p 53$ gene is likely to promote neoplastic transformation of synovial cells that may subsequently contribute to disease progression and joint destruction.

Oxidative stress may also contribute to somatic mtDNA mutation. mtDNA mutations were known to have a key role in ageing-related diseases and carcinogenesis. Currently, there is a growing body of evidence suggesting the role of mitochondrial alterations in rheumatoid disorders [46]. Recent studies showed higher accumulation of mtDNA damage in chondrocytes from OA patients compared with those from normal donors [47]. Higher incidence of mtDNA somatic mutations has also been detected in synoviocytes and synovial tissue of RA than OA controls [48]; however, the frequency of mitochondrial mutations has not been examined. Recently, using synovial tissue of baseline IA patients, we have screened a large number of mtDNA molecules for the presence of unexpanded random mutations, which may be crucial in driving disease progression. We demonstrated, for the first time that greater levels of mtDNA point mutations were 
significantly associated with higher hypoxia in vivo, oxidative stress and disease activity [49].

TNF- $\alpha$ was demonstrated to induce in vitro mitochondrial ROS release and DNA damage in human chondrocytes and overexpression of the DNA repair enzyme prevents mtDNA alterations following TNF- $\alpha$ exposure [50]. In this study, we determined whether TNF therapy affect the levels of mtDNA mutations. We observed that the increase in $\mathrm{tpO}_{2}$ after treatment was associated with significant decrease in the levels of mtDNA mutations and reduction of disease activity scores DAS28-CRP. Contrary, no significant improvements in the levels of mtDNA mutations and DAS28CRP were found in patients who had more hypoxic synovium after receiving TNF blocking treatment. Our findings strongly support the hypothesis that an increase in mutation frequency is a consequence of elevated hypoxia and oxidative damage to the mitochondrial genome. Furthermore, our results are in agreement with another report indicating the role of oxidative stress and diminished mtDNA integrity in the progression of OA, where high levels of mutagenesis following exposure to ROS were associated with reduced mtDNA capacity and cell viability [47]. In addition, our study is the first to show that successful anti-TNF- $\alpha$ therapy reduces the frequency of mitochondrial synovial mutagenesis in IA. It may suggest a central role of mitochondrial mutagenesis in the cellular mechanism of anti-TNF- $\alpha$ response or resistance to the treatment

\section{Conclusions}

We have clearly demonstrated a close association between oxidative stress, mitochondrial mutagenesis and clinical responses to TNF-blocking therapy in IA patients. The greater mitochondrial mutation burden in synovial tissue is associated with higher hypoxia levels in vivo and these significant mitochondrial genome alterations are rescued following successful anti-TNF treatment.

\footnotetext{
Abbreviations

4-HNE: 4-hydroxy-2-nonenal; CRP: C-reactive protein; DAS28-CRP: 28-joint count disease activity score using C-reactive protein; DMARDs: diseasemodifying anti-rheumatic drug; ESR: erythrocyte sedimentation rate; ETC: electron transport chain; IA: inflammatory arthritis; mtDNA: mitochondrial DNA; MTX: methotrexate; NF-kB: nuclear factor-kappa B; OA: osteoarthritis; PBS: phosphate-buffered saline; PSA: psoriatic arthritis; RA: rheumatoid arthritis; ROS: reactive oxygen species; SJC-28: swollen joint count for 28 joints; T0: timepoint 0 or baseline; T3: timepoint three months after starting therapy; TJC-28: tender joint count for 28 joints; TNF-a: tumour necrosis factor alpha; $\mathrm{tpO}_{2}$ : tissue oxygen partial pressure; VAS: visual analogue scale; VEGF: vascular endothelial growth factor.
}

\section{Acknowledgements}

This work was funded by the Health Research Board of Ireland (R10238 and JRFC-05-01).

\section{Author details}

${ }^{1}$ Translation Rheumatology Research Group, Dublin Academic Medical Centre, The Conway Institute of Biomolecular and Biomedical Research, St. Vincent's University Hospital, Elm Park, Dublin 4, Ireland. 'Department of Pathology, University of Washington, 1959 NE Pacific St, HSB k056, Seattle, WA 98195, USA. ${ }^{3}$ Department of Surgery, Institute of Molecular Medicine, Trinity Centre for Health Sciences, St James's Hospital, St James's Hospital, St James's Street, Dublin 8, Ireland.

\section{Authors' contributions}

$\mathrm{MB}$ conducted most of the experiments and analysis of data. AK, CTN, TCC, $E B, E F$ and UF performed some of the experiments. JNO, UF, DV and MB participated in the data analysis and manuscript preparation and final approval of the version to be published. JNO, UF and DV participated in the study design and supervised the research. DV and CTN recruited all patients, performed the arthroscopies and oxygen measurements and provided all clinical information. All authors read and approved the final manuscript.

\section{Competing interests}

The authors declare that they have no competing interests.

Received: 16 March 2011 Revised: 2 June 2011 Accepted: 25 July 2011 Published: 25 July 2011

\section{References}

1. Hamanaka RB, Chandel NS: Mitochondrial reactive oxygen species regulate hypoxic signaling. Curr Opin Cell Biol 2009, 21:894-899.

2. Ralph SJ, Rodriguez-Enriquez S, Neuzil J, Saavedra E, Moreno-Sanchez R: The causes of cancer revisited: "mitochondrial malignancy" and ROS-induced oncogenic transformation - why mitochondria are targets for cancer therapy. Mol Aspects Med 2010, 31:145-170.

3. Poyton RO, Castello PR, Ball KA, Woo DK, Pan N: Mitochondria and hypoxic signaling: a new view. Ann N Y Acad Sci 2009, 1177:48-56

4. Reuter S, Gupta SC, Chaturvedi MM, Aggarwal BB: Oxidative stress, inflammation, and cancer: how are they linked? Free Radic Biol Med 2010, 49:1603-1616.

5. Wallace DC: The mitochondrial genome in human adaptive radiation and disease: on the road to therapeutics and performance enhancement. Gene 2005, 354:169-180.

6. Taylor RW, Turnbull DM: Mitochondrial DNA mutations in human disease. Nat Rev Genet 2005, 6:389-402.

7. Catala A: Lipid peroxidation of membrane phospholipids generates hydroxy-alkenals and oxidized phospholipids active in physiological and/or pathological conditions. Chem Phys Lipids 2009, 157:1-11.

8. Yang Y, Sharma R, Sharma A, Awasthi S, Awasthi YC: Lipid peroxidation and cell cycle signaling: 4-hydroxynonenal, a key molecule in stress mediated signaling. Acta Biochim Pol 2003, 50:319-336.

9. Poli G, Biasi F, Leonarduzzi G: 4-Hydroxynonenal-protein adducts: A reliable biomarker of lipid oxidation in liver diseases. Mol Aspects Med 2008, 29:67-71.

10. Roede JR, Jones DP: Reactive species and mitochondrial dysfunction: mechanistic significance of 4-hydroxynonenal. Environ Mol Mutagen 2010, 51:380-390

11. Nair $U$, Bartsch $H$, Nair J: Lipid peroxidation-induced DNA damage in cancer-prone inflammatory diseases: a review of published adduct types and levels in humans. Free Radic Biol Med 2007, 43:1109-1120.

12. Karouzakis E, Neidhart M, Gay RE, Gay S: Molecular and cellular basis of rheumatoid joint destruction. Immunol Lett 2006, 106:8-13.

13. Tak PP, Firestein GS: NF-kappaB: a key role in inflammatory diseases. $J$ Clin Invest 2001, 107:7-11.

14. Woo CH, Eom YW, Yoo MH, You HJ, Han HJ, Song WK, Yoo YJ, Chun JS, Kim JH: Tumor necrosis factor-alpha generates reactive oxygen species via a cytosolic phospholipase A2-linked cascade. J Biol Chem 2000, 275:32357-32362.

15. Sakon S, Xue X, Takekawa M, Sasazuki T, Okazaki T, Kojima Y, Piao JH, Yagita H, Okumura K, Doi T, Nakano H: NF-kappaB inhibits TNF-induced accumulation of ROS that mediate prolonged MAPK activation and necrotic cell death. EMBO J 2003, 22:3898-3909.

16. Kageyama $Y$, Takahashi M, Ichikawa T, Torikai E, Nagano A: Reduction of oxidative stress marker levels by anti-TNF-alpha antibody, infliximab, in patients with rheumatoid arthritis. Clin Exp Rheumatol 2008, 26:73-80. 
17. Kennedy A, Ng CT, Chang TC, Biniecka M, O'Sullivan J N, Heffernan E, Fearon U, Veale DJ: TNF blocking therapy alters joint inflammation and hypoxia. Arthritis Rheum 2011, 63:923-932.

18. Veale D, Rogers S, Fitzgerald O: Classification of clinical subsets in psoriatic arthritis. Br J Rheumatol 1994, 33:133-138.

19. Arnett FC, Edworthy SM, Bloch DA, MCShane DJ, Fries JF, Cooper NS, Healey LA, Kaplan SR, Liang MH, Luthra HS: The American Rheumatism Association 1987 revised criteria for the classification of rheumatoid arthritis. Arthritis Rheum 1988, 31:315-324.

20. Biniecka M, Kennedy A, Fearon U, Ng CT, Veale DJ, O'Sullivan JN: Oxidative damage in synovial tissue is associated with in vivo hypoxic status in the arthritic joint. Ann Rheum Dis 2010, 69:1172-1178.

21. Youssef PP, Kraan M, Breedveld F, Bresnihan B, Cassidy N, Cunnane G, Emery P, Fitzgerald O, Kane D, Lindblad S, Reece R, Veale D, Tak PP: Quantitative microscopic analysis of inflammation in rheumatoid arthritis synovial membrane samples selected at arthroscopy compared with samples obtained blindly by needle biopsy. Arthritis Rheum 1998 41:663-669.

22. Vermulst M, Bielas $J H$, Loeb LA: Quantification of random mutations in the mitochondrial genome. Methods 2008, 46:263-268.

23. Mirshafiey A, Mohsenzadegan M: The role of reactive oxygen species in immunopathogenesis of rheumatoid arthritis. Iran J Allergy Asthma Immunol 2008, 7:195-202

24. Henrotin YE, Bruckner P, Pujol JP: The role of reactive oxygen species in homeostasis and degradation of cartilage. Osteoarthritis Cartilage 2003, 11:747-755.

25. Tsay J, Yang Z, Ross FP, Cunningham-Rundles S, Lin H, Coleman R, MayerKuckuk P, Doty SB, Grady RW, Giardina PJ, Boskey AL, Vogiatzi MG: Bone loss caused by iron overload in a murine model: importance of oxidative stress. Blood 2010, 116:2582-2589.

26. Ng CT, Biniecka M, Kennedy A, McCormick J, Fitzgerald O, Bresnihan B, Buggy D, Taylor CT, O'Sullivan J, Fearon U, Veale DJ: Synovial tissue hypoxia and inflammation in vivo. Ann Rheum Dis 2010, 69:1389-1395.

27. Suffys $P$, Beyaert $R$, De Valck D, Vanhaesebroeck B, Van Roy F, Fiers W: Tumour-necrosis-factor-mediated cytotoxicity is correlated with phospholipase-A2 activity, but not with arachidonic acid release per se. Eur J Biochem 1991, 195:465-475.

28. Ruggiero $V$, Johnson SE, Baglioni C: Protection from tumor necrosis factor cytotoxicity by protease inhibitors. Cell Immunol 1987, 107:317-325

29. Dealtry GB, Naylor MS, Fiers W, Balkwill FR: DNA fragmentation and cytotoxicity caused by tumor necrosis factor is enhanced by interferongamma. Eur J Immunol 1987, 17:689-693.

30. Miesel R, Murphy MP, Kroger H: Enhanced mitochondrial radical production in patients which rheumatoid arthritis correlates with elevated levels of tumor necrosis factor alpha in plasma. Free Radic Res 1996, 25:161-169.

31. Schulze-Osthoff K, Beyaert R, Vandevoorde V, Haegeman G, Fiers W: Depletion of the mitochondrial electron transport abrogates the cytotoxic and gene-inductive effects of TNF. EMBO J 1993, 12:3095-3104

32. Echtay KS, Esteves TC, Pakay $J$, Jekabsons MB, Lambert AJ, Portero-Otin M Pamplona R, Vidal-Puig AJ, Wang S, Roebuck SJ, Brand MD: A signalling role for 4-hydroxy-2-nonenal in regulation of mitochondrial uncoupling EMBO J 2003, 22:4103-4110.

33. Chen JJ, Bertrand H, Yu BP: Inhibition of adenine nucleotide translocator by lipid peroxidation products. Free Radic Biol Med 1995, 19:583-590.

34. Kageyama Y, Takahashi M, Nagafusa T, Torikai E, Nagano A: Etanercept reduces the oxidative stress marker levels in patients with rheumatoid arthritis. Rheumatol Int 2008, 28:245-251.

35. Remans PH, van Oosterhout M, Smeets TJ, Sanders M, Frederiks WM, Reedquist KA, Tak PP, Breedveld FC, van Laar JM: Intracellular free radical production in synovial $\mathrm{T}$ lymphocytes from patients with rheumatoid arthritis. Arthritis Rheum 2005, 52:2003-2009.

36. Kurien BT, Scofield RH: Autoimmunity and oxidatively modified autoantigens. Autoimmun Rev 2008, 7:567-573.

37. Kumagai T, Matsukawa N, Kaneko Y, Kusumi Y, Mitsumata M, Uchida K: A lipid peroxidation-derived inflammatory mediator: identification of 4hydroxy-2-nonenal as a potential inducer of cyclooxygenase-2 in macrophages. J Biol Chem 2004, 279:48389-48396.

38. Shi $Q$, Vaillancourt F, Cote V, Fahmi H, Lavigne $P$, Afif $H$, Di Battista JA, Fernandes JC, Benderdour M: Alterations of metabolic activity in human osteoarthritic osteoblasts by lipid peroxidation end product 4hydroxynonenal. Arthritis Res Ther 2006, 8:R159.

39. Ayalasomayajula SP, Kompella UB: Induction of vascular endothelial growth factor by 4-hydroxynonenal and its prevention by glutathione precursors in retinal pigment epithelial cells. Eur J Pharmacol 2002, 449:213-220.

40. Ruef J, Hu ZY, Yin LY, Wu Y, Hanson SR, Kelly AB, Harker LA, Rao GN, Runge MS, Patterson C: Induction of vascular endothelial growth factor in balloon-injured baboon arteries. A novel role for reactive oxygen species in atherosclerosis. Circ Res 1997, 81:24-33.

41. Mulherin D, Fitzgerald O, Bresnihan B: Clinical improvement and radiological deterioration in rheumatoid arthritis: evidence that the pathogenesis of synovial inflammation and articular erosion may differ. Br J Rheumatol 1996, 35:1263-1268.

42. Firestein GS, Echeverri F, Yeo M, Zvaifler NJ, Green DR: Somatic mutations in the p53 tumor suppressor gene in rheumatoid arthritis synovium. Proc Natl Acad Sci USA 1997, 94:10895-10900.

43. Tak PP, Zvaifler NJ, Green DR, Firestein GS: Rheumatoid arthritis and p53: how oxidative stress might alter the course of inflammatory diseases. Immunol Today 2000, 21:78-82.

44. Lee SH, Chang DK, Goel A, Boland CR, Bugbee W, Boyle DL, Firestein GS: Microsatellite instability and suppressed DNA repair enzyme expression in rheumatoid arthritis. J Immunol 2003, 170:2214-2220.

45. Tak PP, Smeets TJ, Boyle DL, Kraan MC, Shi Y, Zhuang S, Zvaifler NJ, Breedveld FC, Firestein GS: p53 overexpression in synovial tissue from patients with early and longstanding rheumatoid arthritis compared with patients with reactive arthritis and osteoarthritis. Arthritis Rheum 1999, 42:948-953.

46. Ospelt C, Gay S: Somatic mutations in mitochondria: the chicken or the egg? Arthritis Res Ther 2005, 7:179-180

47. Grishko VI, Ho R, Wilson GL, Pearsall AWt: Diminished mitochondrial DNA integrity and repair capacity in OA chondrocytes. Osteoarthritis Cartilage 2009, 17:107-113.

48. Da Sylva TR, Connor A, Mburu Y, Keystone E, Wu GE: Somatic mutations in the mitochondria of rheumatoid arthritis synoviocytes. Arthritis Res Ther 2005, 7:R844-851.

49. Biniecka M, Fox E, Gao W, Ng CT, Veale DJ, Fearon U, O'Sullivan J: Hypoxia induces mitochondrial mutagenesis and dysfunction in inflammatory arthritis. Arthritis Rheum 2011.

50. Kim J, Xu M, Xo R, Mates A, Wilson GL, Pearsall AWt, Grishko V: Mitochondrial DNA damage is involved in apoptosis caused by proinflammatory cytokines in human OA chondrocytes. Osteoarthritis Cartilage 2010, 18:424-432.

\section{doi:10.1186/ar3424}

Cite this article as: Biniecka et al:: Successful tumour necrosis factor (TNF) blocking therapy suppresses oxidative stress and hypoxia-induced mitochondrial mutagenesis in inflammatory arthritis. Arthritis Research \& Therapy 2011 13:R121.

\section{Submit your next manuscript to BioMed Central and take full advantage of:}

- Convenient online submission

- Thorough peer review

- No space constraints or color figure charges

- Immediate publication on acceptance

- Inclusion in PubMed, CAS, Scopus and Google Scholar

- Research which is freely available for redistribution

Submit your manuscript at www.biomedcentral.com/submit
C Biomed Central 